\title{
Allosteric small-molecule kinase inhibitors
}

\section{Wu, Peng; Clausen, Mads Hartvig; Nielsen, Thomas E.}

\section{Published in:}

Pharmacology \& Therapeutics

Link to article, DOI:

10.1016/j.pharmthera.2015.10.002

Publication date:

2015

Document Version

Peer reviewed version

Link back to DTU Orbit

Citation (APA):

Wu, P., Clausen, M. H., \& Nielsen, T. E. (2015). Allosteric small-molecule kinase inhibitors. Pharmacology \& Therapeutics, 156, 56-68. https://doi.org/10.1016/j.pharmthera.2015.10.002

\section{General rights}

Copyright and moral rights for the publications made accessible in the public portal are retained by the authors and/or other copyright owners and it is a condition of accessing publications that users recognise and abide by the legal requirements associated with these rights.

- Users may download and print one copy of any publication from the public portal for the purpose of private study or research.

- You may not further distribute the material or use it for any profit-making activity or commercial gain

- You may freely distribute the URL identifying the publication in the public portal

If you believe that this document breaches copyright please contact us providing details, and we will remove access to the work immediately and investigate your claim 


\section{Allosteric small-molecule kinase inhibitors}

Peng Wu ${ }^{\mathrm{a}, *}$, Mads H. Clausen ${ }^{\mathrm{a}, \mathrm{b}}$, Thomas E. Nielsen ${ }^{\mathrm{c}}$

${ }^{a}$ Department of Chemistry, Technical University of Denmark, Kgs. Lyngby DK-2800, Denmark

${ }^{\mathrm{b}}$ Center for Nanomedicine and Theranostics, Technical University of Denmark, Kgs. Lyngby DK2800, Denmark

${ }^{c}$ Protein and Peptide Chemistry, Novo Nordisk A/S, Måløv DK-2760, Denmark

*Corresponding author at: Department of Chemistry, Technical University of Denmark, Kgs. Lyngby DK-2800, Denmark. Tel: +45 5239 9298; Fax: +45 45252116

E-mail address: penwu@kemi.dtu.dk (P. Wu) 


\begin{abstract}
:
Small-molecule kinase inhibitors are invaluable targeted therapeutics for the treatment of various human diseases, especially cancers. While the majority of approved and developed preclinical small-molecule inhibitors are characterized as type I or type II inhibitors that target the ATPbinding pocket of kinases, the remarkable sequential and structural similarity among ATP pockets renders the selective inhibition of kinases a daunting challenge. Therefore, targeting allosteric pockets of kinases outside the highly conversed ATP pocket has been proposed as a promising alternative to overcome current barriers of kinase inhibitors, including poor selectivity and emergence of drug resistance. In spite of the small number of identified allosteric inhibitors in comparison with that of inhibitors targeting the ATP pocket, encouraging results, such as the FDAapproval of the first small-molecule allosteric inhibitor trametinib in 2013, the progress of more than 10 other allosteric inhibitors in clinical trials, and the emergence of a pipeline of highly selective and potent preclinical molecules, have been reported in the past decade. In this article, we present the current knowledge on allosteric inhibition in terms of conception, classification, potential advantages, and summarized debatable topics in the field. Recent progress and allosteric inhibitors that were identified in the past three years are highlighted in this paper.
\end{abstract}




\section{Keywords:}

Allosteric inhibitors

Serine/threonine kinase

Tyrosine kinase

MEK inhibitors

Type III inhibitors

Type IV inhibitors 


\section{List of Abbreviations:}

AGC, containing protein kinase $\mathrm{A}$, protein kinase $\mathrm{G}$, protein kinase $\mathrm{C}$ families;

ATP, adenosine 5'-triphosphate;

CAMK, calcium/calmodulin-dependent protein kinases;

CDK, cyclin-dependent kinase;

CHK1, checkpoint kinase 1;

CMKC, containing CDK, MAPK, GSK3, CLK families;

DFG, aspartate-phenylalanine-glycine residues;

FAK, focal adhesion kinase;

FDA, United States Food and Drug Administration;

IGF-1R, insulin-like growth factor-1 receptor;

IKK, IкB kinase;

IRE1, inositol requiring enzyme 1;

ITK, interleukin-2-inducible T-cell kinase;

JNK, c-Jun N-terminal kinase;

LIMK, LIM (Lin11, Is11 \& Mec3) domain-containing kinase;

MAPK, mitogen-activated protein kinase (also known as ERK, extracellular signal-regulated kinase); 
MAPKK, mitogen-activated protein kinase kinase (also known as MEK, mitogen/extracellular signal-regulated kinase);

mTOR, mammalian target of rapamycin;

NSCLC, non-small cell lung cancer;

PAK1, p21-activated kinase 1;

PDK1, phosphoinositide-dependent kinase1;

PH domain, pleckstrin homology domain;

PIF, PDK1-interacting fragment;

PI3K, phosphatidylinositol 3-kinase;

PIKK, phosphatidylinositol 3-kinase-like protein kinases;

$\mathrm{PKB}$, protein kinase $\mathrm{B}$ (also known as Akt);

PKC, protein kinase $C$;

RIP1, receptor-interacting protein kinase 1;

SMKIs, small-molecule kinase inhibitors;

STE, homologs of yeast Sterile 7, Sterile 11, and Sterile 20 kinases;

TK, tyrosine kinase;

TKL, tyrosine kinase-like. 
Table of Contents:

1. Introduction: kinase inhibition

2. Understanding allosteric kinase inhibitors

3. Allosteric serine/threonine kinase inhibitors

4. Allosteric tyrosine kinase inhibitors

5. Other allosteric kinase inhibitors

6. Perspectives

7. Conclusion

Conflict of interest

Acknowledgement

References 


\section{Introduction: kinase inhibition}

Kinases transfer the gamma phosphate of ATP onto hydroxyl bearing substrates including proteins, lipids, and sugars, and are implicated in various cellular and extracellular activities (Johnson \& Lewis, 2001). Overexpression and dysregulation of kinases are directly associated with many human diseases. Inhibition of kinases by small molecules can severely impair activation of crucial cellular signaling pathways. Initiated by pioneering work performed before the $1980 \mathrm{~s}$ in the field, small molecule kinase inhibitors (SMKIs) entered the clinical stage in the 1990s, followed by a "sprouting decade of kinase inhibitors" research from 2001 to 2010 that was effectively kicked off by the FDA-approval of imatinib for the treatment of patients with chronic myeloid leukemia. As of July 2015, a total of 28 FDA-approved SMKIs (P. Wu et al., 2015a), together with a few more approved by drug administrations of other countries, are on the market. Encouraged by the success of SMKIs in clinical settings, kinases are now being intensively studied as key therapeutic targets in drug discovery (Fabbro et al., 2015), especially for the treatment of different types of human cancers (P. Wu et al., 2015b). In parallel, kinases have been indicated as potent therapeutic targets in targeting inflammatory diseases, cardiovascular diseases, diabetes, and also in neurological disorders, such as Alzheimer's and Parkinson's disease (Rask-Andersen et al., 2014).

However, a few factors collectively undermine the clinical applications of SMKIs. Many reported kinase inhibitors, including approved drugs, suffer from undesired selectivity profiles (Davis et al., 2011; Norman et al., 2012). Low specificity towards the target kinase and a lack of selectivity for structurally related kinase families may lead to side effects and off-target toxicity in clinical settings. In addition, the emergence of resistance due to site mutations in the ATP binding pocket also limits the use of SMKIs in cancer treatment. Since most developed SMKIs target the highly conserved ATP binding pocket, an alternative inhibition approach that targets other less- 
conserved allosteric pockets in the kinase domain, or other remote sites, is being actively pursued (Foda \& Seeliger, 2014).

\section{Understanding allosteric kinase inhibitors}

The majority of non-covalent SMKIs are ATP-competitive inhibitors, classified as either type I or type II inhibitors, by reference to the conformation of the highly conserved aspartatephenylalanine-glycine (DFG)-motif in the beginning of the activation loop in the C-lobe of the kinase domain (P. Wu et al., 2015a). Type I inhibitors, such as gefitinib (Iressa®), bind in the ATP pocket of the active kinase form with a "DFG-in" conformation. Type II inhibitors, such as imatinib (Gleevec ${ }^{\circledR}$ ), bind in the hinge region of the ATP pocket and a less conserved allosteric region that is formed following the conformational change to the "DFG-out" motif, and stabilize the inactive form of the kinase. In contrast, allosteric inhibitors are defined as molecules that bind outside the ATP-binding pocket with no interaction with the hinge region that connects the $\mathrm{N}$ - and C-lobes of the kinase domain. Allosteric inhibitors can be classified as type III inhibitors, such as cobimetinib, which bind in an adjacent allosteric site that does not overlap with the ATP binding pocket/hinge region (Rice et al., 2012) (Fig. 1A), or type IV inhibitors, such as GNF2, which bind to an allosteric site that is distant from the ATP binding pocket (Zhang et al., 2010) (Fig. 1B). There are different definitions for other types of non-covalent SMKIs, which are referred to as type V inhibitors in this manuscript. Type V inhibitors include a small group of bivalent or bisubstrate inhibitors (Gower et al., 2014; Lamba \& Ghosh, 2012), and a few inhibitors with hybrid type I and II features (Okamoto et al., 2015), which has also been referred to as type 11/2 inhibitors (Zuccotto et al., 2010). Even though most allosteric SMKIs are non-ATP competitive, as they bind into a site that does no overlap with the ATP-binding site, some allosteric SMKIs may still be ATP-competitive due to stabilization of the inactive conformation of their binding kinases (Cowan-Jacob et al., 2014). 

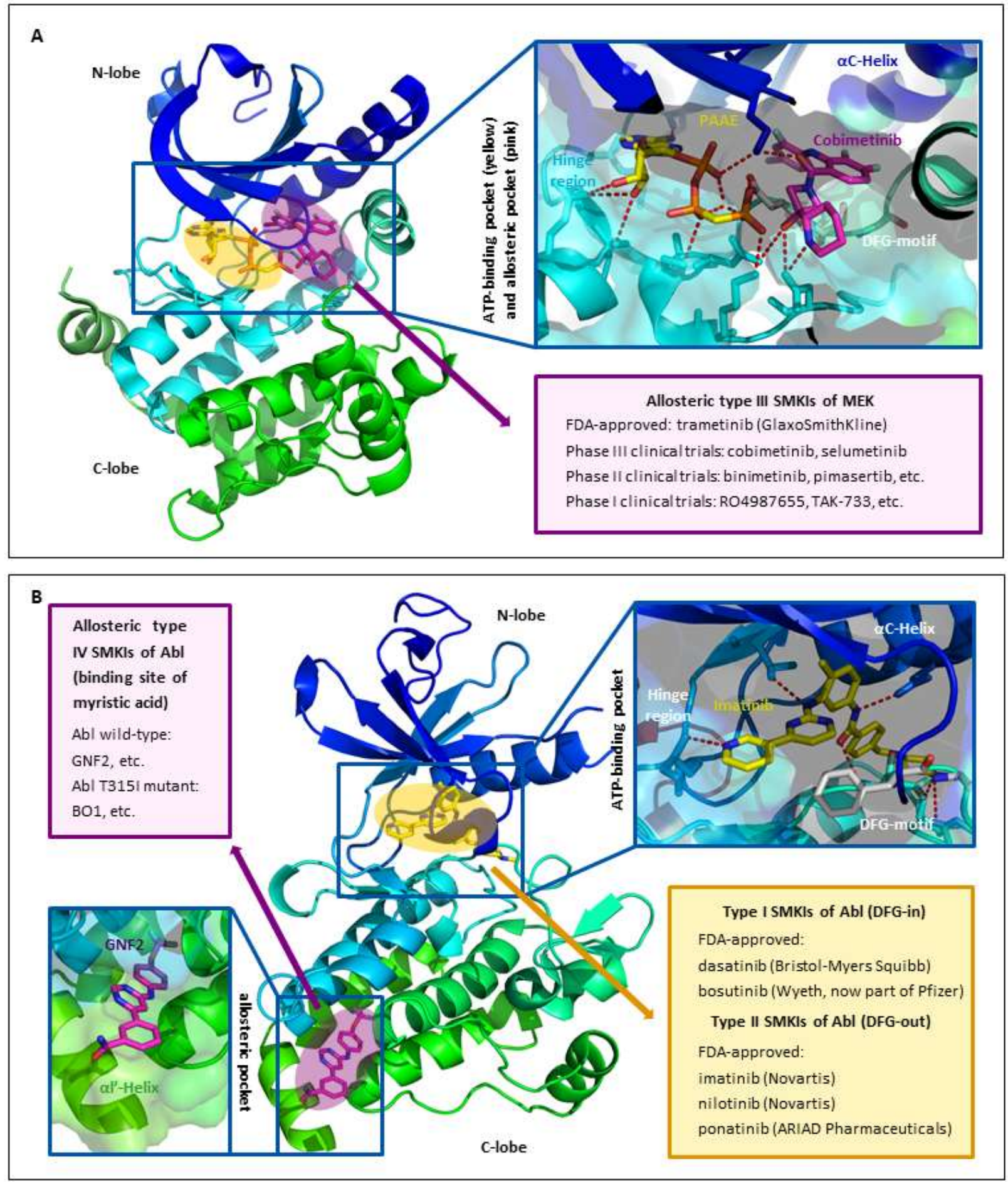

Fig. 1. Two types of allosteric SMKIs. (A) Allosteric type III inhibitors bind into a pocket adjacent to the ATP-binding site, as exemplified by the cobimetinib-MEK1 co-crystal structure (PDB ID: 4AN2, $2.50 \AA$ ). The molecule bound in the ATP-binding pocket is phosphomethylphosphonic acid adenylate ester (PAAE); (B) Allosteric type IV inhibitors bind in a pocket distal to the ATP-binding site, as exemplified by the GNF2-Abl co-crystal structure (PDB ID: 3K5V, 1.74 
A). The molecule bound in the ATP-binding pocket is imatinib. The SH3 domain, SH2 domain, and the linker between $\mathrm{SH} 2$ and N-lobe are not included in the GNF2-Abl co-crystal structure with imatinib. Hydrogen bond interactions are indicated with red dotted lines, molecules bound in the ATP-binding pocket are shown with yellow backbones, allosteric inhibitors are shown with magenta backbones, and the residues of the DFG-motif are shown with white backbones.

The field of allosteric kinase inhibition has evolved rapidly in the past few years with the FDA-approval of trametinib as the first allosteric SMKI, the progression of more than 10 other allosteric inhibitors of MEK and Akt in clinical trials, and examples of allosteric inhibitors of LIMK2, PAK, IRE1, and RIP1 being reported for the first time.

The comparatively low sequence homology of allosteric sites provides unique opportunities for more specific inhibition and minimal off-target pharmacology (Fang et al., 2013). Other advantages of allosteric inhibitors over traditional ATP-competitive type I and II inhibitors include the potential to overcome mutation-associated drug-resistance, especially mutations in the ATP-binding site that confer resistance to almost all related ATP-competitive inhibitors, such as the frequently occurring T315I mutations in the gatekeeper residue Abl (Gibbons et al., 2012) In addition, SMKIs may not need to exhibit nanomolar affinity to compete with the high intracellular ATP concentrations, making it easier to identify weak binding inhibitors, ranging from fragments to hit and lead compounds, and treatment of indications beyond cancer may be feasible. Furthermore, allosteric SMKIs can find utility as selective chemical probes to facilitate mechanistic studies on molecular function. With these attractive features, allosteric inhibitors are now being extensively studied as a new generation of SMKIs.

As previous articles have analyzed the structural basis (Fang et al., 2013), and discussed the potential and opportunities (Cowan-Jacob et al., 2014), for allosteric inhibition, this review will highlight recent development on small-molecule allosteric inhibitors that have already progressed in 
clinical trials and inhibitors that were revealed in the past three years. Inhibitors that disrupt proteinprotein interactions are not covered in this discussion.

\section{Allosteric serine/threonine kinase inhibitors}

The signaling cascades of Ras-Raf-mitogen/extracelluar signal-regulated kinase (MEK) pathway (Samatar \& Poulikakos, 2014) and phosphatidylinositol 3-kinase (PI3K)-Akt-mammalian target of rapamycin (mTOR) pathway are among the most frequently dysregulated signaling networks in human malignancies (Fruman \& Rommel, 2014; Houédé \& Pourquier, 2015). A large number of structurally diverse small molecules have been reported as inhibitors of key kinases through both pathways. The serine/threonine kinases MEK and Akt are among the most thoroughlyinvestigated targets for which allosteric inhibitors have been developed (Fasano et al., 2014).

\subsection{MAPKK and MAPK inhibitors}

Mitogen/extracellular signal-regulated kinase (MEK), also known as mitogen-activated protein kinase kinase (MAPKK), is a dual specificity threonine/tyrosine kinase that plays a critical role in the Raf-Ras-MEK signaling pathway. A selection of highly selective and potent allosteric non-ATP competitive MEK inhibitors are currently in clinical trials of different phases for the treatment of non-small cell lung cancer (NSCLC) (Zhao \& Adjei, 2014).

The MEK1/2 inhibitor trametinib (1, Mekinist ${ }^{\circledR}$, originally developed by GlaxoSmithKline, but owned by Novartis starting from May 2015) is the first and only approved allosteric SMKI, whose structural-activity relationship and pharmacological profile have been widely studied (Abe et al., 2011). Trametinib was approved by FDA in May 2013 as a single-agent for the treatment of patients with either B-Raf V600E or V600K mutated metastatic melanoma. Most common adverse reactions of trametinib in more than $20 \%$ of patients are rash, diarrhea, and lymphedema, which are also common adverse reactions for many other approved SMKIs. To overcome the observed 
progression using single-agent trametinib, which usually occurs within 7 months, combination strategies using the B-Raf inhibitor dabrafenib was evaluated and shown to delay the emergence of resistance and significantly improve survival without increased overall toxic effects (Long et al., 2014; Robert et al., 2015). FDA approved the combination of dabrafenib and trametinib for the treatment of B-Raf V600E/K mutated metastatic melanoma in January 2014.

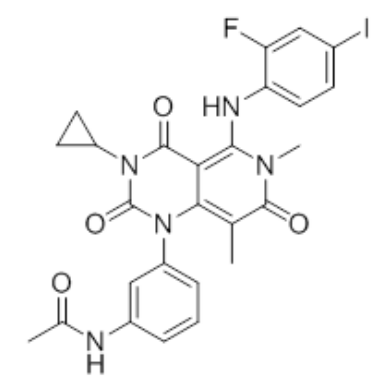

Trametinib/GSK1120212 (1) FDA-approved<smiles>O=C(NC[C@H](O)CO)c1ccncc1Nc1ccc(I)cc1F</smiles>

Pimasertib (5) Phase II

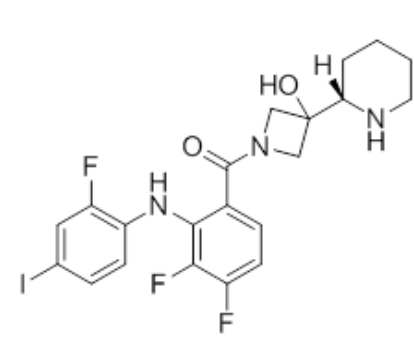

Cobimetinib (2) Phase III

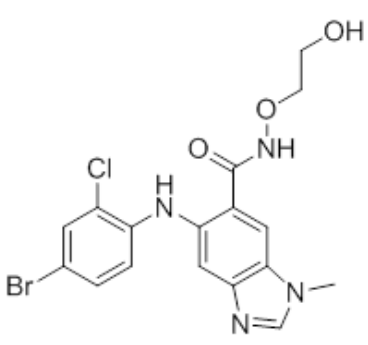

Selumetinib/AZD6244 (3) Phase III

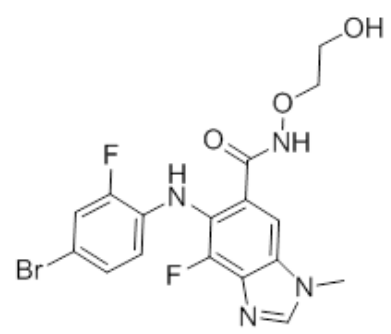

Binimetinib/MEK162 (4) Phase II<smiles>COc1cc(F)c(F)c(Nc2ccc(I)cc2F)c1NS(=O)(=O)C1(C[C@@H](O)CO)CC1</smiles>

Refametinib (6) Phase II<smiles>O=C(NOCC1CC1)c1ccc(F)c(F)c1Nc1ccc(I)cc1Cl</smiles>

Cl-1040/PD184352 (7) Phase II<smiles>O=C(NOCC(O)CO)c1ccc(F)c(F)c1Nc1ccc(I)cc1F</smiles>

PD0325901 (8)

Phase II<smiles>O=C(NOCCO)c1cc(CN2OCCCC2=O)c(F)c(F)c1Nc1ccc(I)cc1F</smiles>

$\mathrm{CH} / \mathrm{RO} 4987655$ (9) Phase I

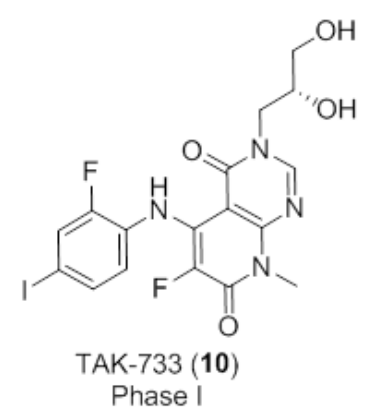

Phase I

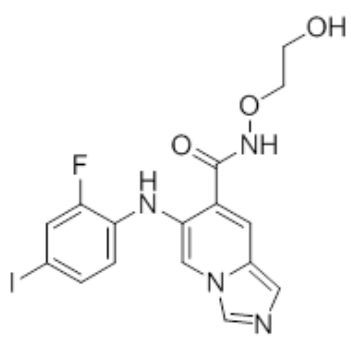

GDC-0623 (11) Phase I

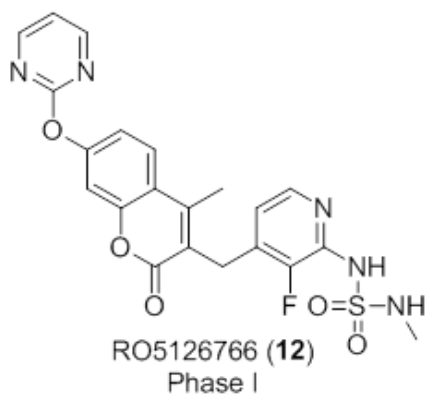

Fig. 2. Approved and clinically investigated allosteric MEK1/2 inhibitors.

Diarylamine compounds comprise for a major class of allosteric MEK1/2 inhibitors (Rice et al., 2012). Cobimetinib (2) is being studied in combination with the FDA-approved B-Raf inhibitor vemurafenib for the treatment of $\mathrm{B}-\mathrm{Raf} \mathrm{V} 600 \mathrm{E} / \mathrm{K}$ mutation-positive advanced melanoma 
(Hatzivassiliou et al., 2013), which has showed a median progression-free survival of 9.9 months compared to 6.2 months using vemurafenib alone, although at the cost of increased toxicity in terms of liver lab value abnormalities, elevated level of creatine phosphokinase, and diarrhea (NCT02427893) (Larkin et al., 2014). This application has been granted a priority review by FDA, and a decision on approval is expected by November 11, 2015.

Selumetinib (3, AstraZeneca) is currently in various active clinical trials on advanced NSCLC (Jänne et al., 2013) and soft-tissue sarcomas (Eroglu et al., 2015), while a phase III study using 75 mg of selumetinib in combination with dacarbazine as first systemic therapy in patients with metastatic uveal melanoma failed to improve progression-free survival compared to dacarbazine alone (NCT01974752).

Other advanced diarylamine compounds with structures closely related to that of cobimetinib and selumetinib include binimetinib (4), pimasertib (5), refametinib (6), PD184352 (7), and PD0325901 (8) in phase II trials, and RO4987655 (9), TAK-733 (10), and GDC-0623 (11) in phase I trials. Phase I compound RO5126766 (12) represents another series of allosteric MEK inhibitors containing a chromen-2-one scaffold (Samatar \& Poulikakos, 2014) (Fig. 2).

Recent examples of preclinical MEK inhibitors include a series of chromone-based structures, such as PD98059 (13) and compound 14, which showed an $\mathrm{IC}_{50}$ value of $30 \mathrm{nM}$ against MEK1 (Redwan et al., 2014) (Fig. 3).

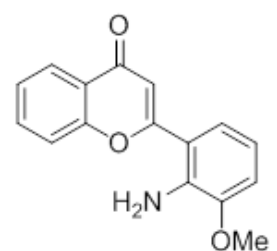

PD98059 (13)

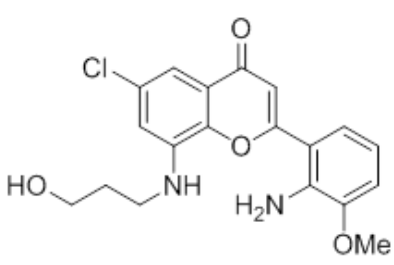

14

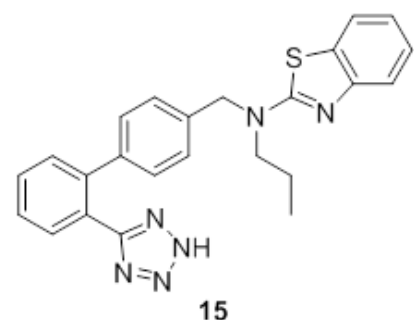

15

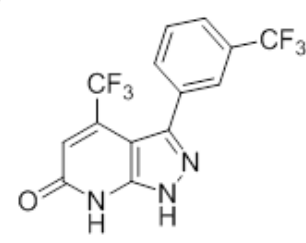

16 
Fig. 3. Preclinical allosteric inhibitors of MAPKK and MAPK.

Mitogen-activated protein kinases (MAP kinases or MAPKs) p38 and c-Jun N-terminal protein kinases (JNKs) are downstream effectors of MAPKK. Biphenyltetrazole compound 15 (inactivated JNK1, $\left.\mathrm{K}_{\mathrm{d}}: 11 \mu \mathrm{M}\right)$, which binds into a pocket located in the MAP insert region that is distant from the ATP-binding pocket, was identified as a type IV allosteric inhibitor of JNK1 by an affinitybased screening approach. The same study unfolded compound $\mathbf{1 6}$ as a selective p38 $\alpha$ inhibitor (p38 $, \mathrm{IC}_{50}: 1.2 \mu \mathrm{M} ; \mathrm{p} 38 \beta, \gamma$, and $\delta, \mathrm{IC}_{50}:>40 \mu \mathrm{M}$ ), which binds into a distal allosteric pocket in the C-lobe of the p38 kinase domain (Comess et al., 2011). A series of natural product derived fragments with a cytisine or sparteine scaffold were recently identified as inhibitors that exclusively bind into the DFG-out pocket of p38 $\alpha$ with weak potencies and low ligand efficiencies (Over et al., 2013). In addition, several pyrazolylureas have been previously reported as potent allosteric p38 inhibitors (Regan et al., 2003).

\subsection{Akt inhibitors}

The serine/threonine kinase Akt, also known as protein kinase $\mathrm{B}(\mathrm{PKB})$, is an important knot in the PI3K/Akt/mTOR signaling cascade, which is tightly associated with cell proliferation, survival, migration, angiogenesis and many other biological activities, especially processes that are directly associated with tumor genesis and progression (Fruman \& Rommel, 2014; P. Wu et al., 2009). Reported ATP-competitive Akt inhibitors have shown poor selectivity against other kinases, especially the closely related ones in the kinase family containing protein kinases $\mathrm{A}, \mathrm{G}$, and C (AGC), let alone the three highly homologous isoforms of Akt (Lindsley, 2010). Akt inhibition is still a challenging issue, as illustrated by the fact that only few lead candidates have been identified so far, despite considerable efforts in both academia and the pharmaceutical industry. 
The best characterized allosteric inhibitor of Akt is the $[1,2,4]$ triazolo[3,4-f][1,6]naphthyridin3-one compound MK-2206 (17) (Hirai et al., 2010), which targets a unique allosteric pocket at the interface of the catalytic kinase domain and the regulatory pleckstrin homology $(\mathrm{PH})$ domain of the inactive conformation of Akt. Compound MK-2206 is currently under investigation in various phase I and II studies on breast cancer, NSCLC, nasopharyngeal carcinoma, colon/rectal and other cancers, with a maximum tolerated dose of $60 \mathrm{mg}$ on alternate days or a weekly intermittent dose of $200 \mathrm{mg}$ (Yap et al., 2014).
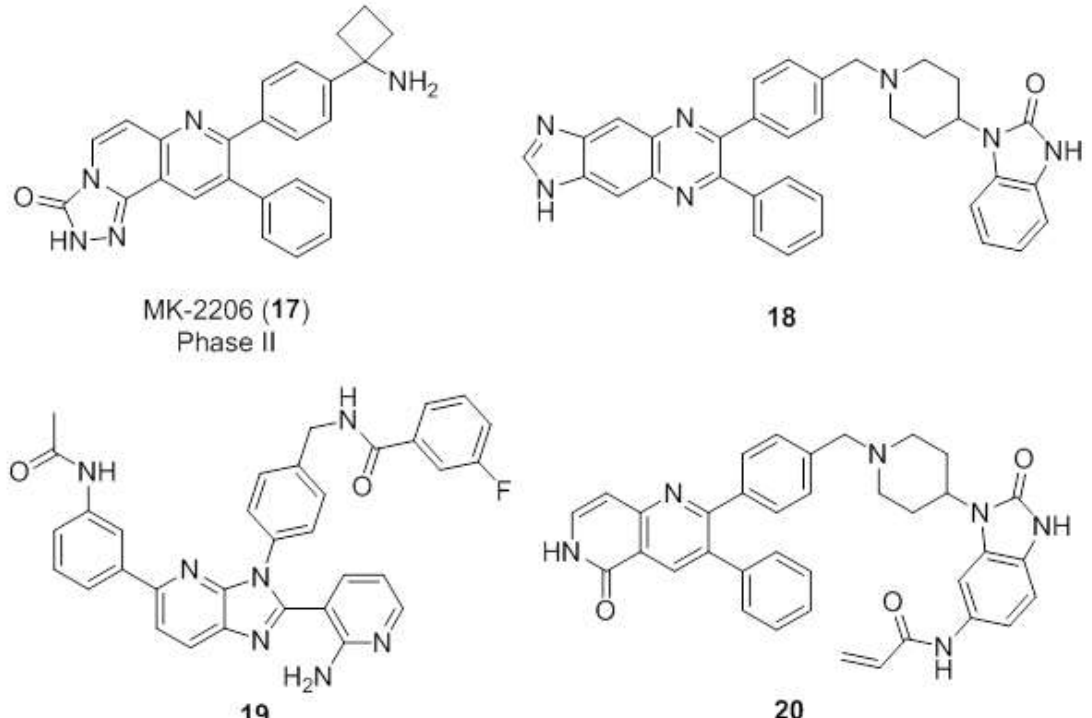

Fig. 4. Allosteric Akt inhibitors.

Based on the structural and binding features of MK-2206, a few more allosteric inhibitors, such as compounds 18 (Akt1, IC $\left.50: 58 \mathrm{nM}, \mathrm{Akt} 2, \mathrm{IC}_{50}: 0.21 \mu \mathrm{M}, \mathrm{Akt} 3, \mathrm{IC}_{50}: 2.1 \mu \mathrm{M}\right)(\mathrm{W} . \mathrm{I}$. Wu et al., 2010) and 19 (Akt1, IC $50: 5 \mathrm{nM}, \mathrm{Akt} 2, \mathrm{IC}_{50}: 18 \mathrm{nM}, \mathrm{Akt} 3, \mathrm{IC}_{50}: 0.17 \mu \mathrm{M}$ ) (Ashwell et al., 2012) (Fig. 4), have been identified and co-crystallized with full-length Akt (Fig. 5). Compound 20 was very recently identified as a potent allosteric and covalent Akt inhibitor with an $\mathrm{IC}_{50}$ value of 0.2 $\mathrm{nM}$ against Akt1. The diphenylnaphthyridinone scaffold of compound $\mathbf{2 0}$ fits into the MK-2206 binding site, and its terminal electrophile forms covalent bonds with Cys296 or Cys310 located on 
the flexible activation loop of Akt. At $1 \mu \mathrm{M}$ concentration, compound 20 showed significant inhibitory potency (>80\%), exclusively against Akt1, Akt2, and Akt3, in a kinase profiling assay. In addition, compound $\mathbf{2 0}$ was also shown to be a cell-permeable effector of Akt in gastrointestinal stromal tumor cells (Weisner et al., 2015).

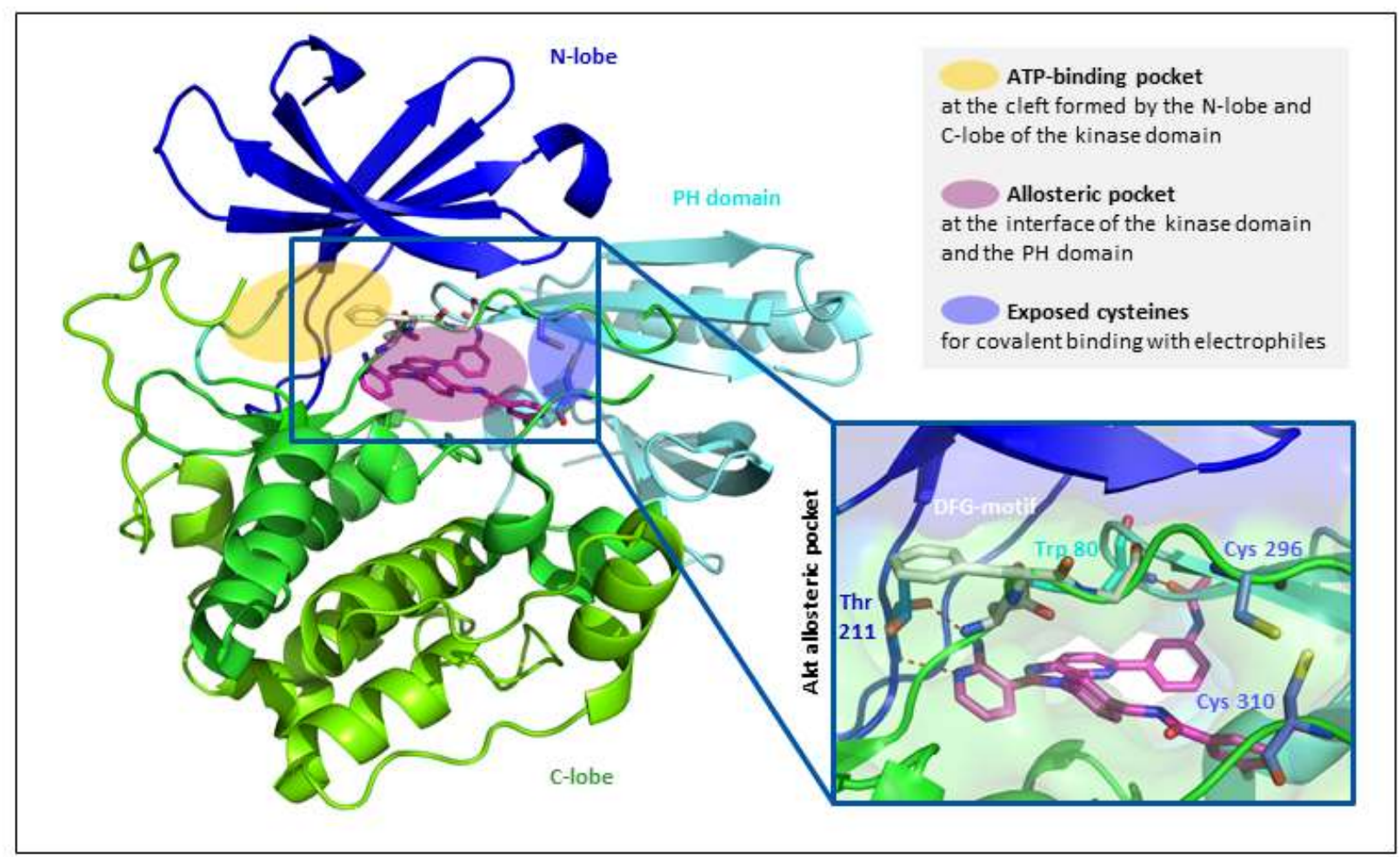

Fig. 5. Allosteric inhibitors of Akt bind in a pocket at the interface of the kinase domain and the PH domain, exemplified by the 19-Akt co-crystal structure (PDB ID: 4EJN, $2.19 \AA$ ). The inactive "DFG-motif out" conformation (detailed view) is stabilized by allosteric inhibition. Hydrogen bond interactions are indicated with red dotted lines, allosteric inhibitor compound $\mathbf{1 9}$ is shown with magenta backbone, the residues of the DFG-motif are shown with white backbones, and the exposed cysteine residues for covalent inhibition with molecules incorporating chemically active Michael acceptor electrophiles are shown with purple backbones.

\subsection{CDK inhibitors}

Following decades of intensive investigation centered around cyclin-dependent kinase (CDK) inhibitors, the CDK4/6 inhibitor palbociclib (Ibrance®, Pfizer) was approved as an ATP- 
competitive inhibitor for the treatment of breast cancer in February 2015 (Lu \& Schulze-Gahmen, 2006). The reservoir of reported CDK inhibitors includes a large number of other potent ATPcompetitive inhibitors (Pitts et al., 2014), while the majority of these compounds have shown undesired selectivity and toxicity. Several allosteric inhibitors with micromolar inhibitory potency against CDK2 were identified through a virtual screening campaign combined with docking analysis. Representative compound (21, Fig. 6) binds into an allosteric pocket of CDK2 formed following displacement of the $\alpha \mathrm{C}$-helix, and showed an $\mathrm{IC}_{50}$ value of $4 \mu \mathrm{M}$ against breast cancer cell lines (Rastelli et al., 2014).

A pyrazolylurea compound (22, Fig. 6), identified in a fragment-based strategy, has been shown to bind deep inside the DMG-out pocket (equivalent to DFG-out pocket of other kinases) of CDK8/CycC complex with a $\mathrm{K}_{\mathrm{d}}$ value of $3.24 \mu \mathrm{M}$, without interacting with the hinge region of CDK8 (E. V. Schneider et al., 2013). Compounds sharing the pyrazolylurea scaffold have also been reported as allosteric inhibitors of the p38 MAPK (Regan et al., 2003) and tyrosine kinase cSrc (Simard, Kluter, et al., 2009).

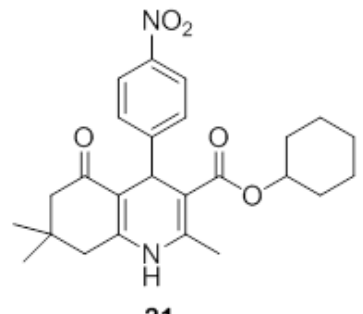

21

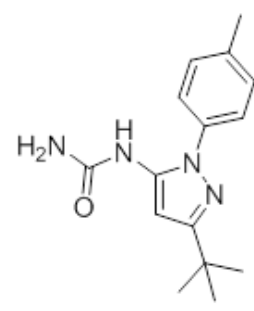

22

Fig. 6. Allosteric CDK inhibitors.

\subsection{LIMK inhibitors}

A series of $N$-phenylsulfonamide compounds, such as compounds $23\left(\mathrm{IC}_{50}: 92 \mathrm{nM}\right), \mathbf{2 4}\left(\mathrm{IC}_{50}\right.$ : $39 \mathrm{nM})$ and $25\left(\mathrm{IC}_{50}: 3 \mathrm{nM}\right)$ (Fig. 7), were recently reported as the first known type III inhibitors of tyrosine-like kinase (TKL) LIM-kinase (LIMK)2. Screening assays against selected kinases from 
TKL, TK, AGC, CAMK, homologs of yeast Sterile 7, 11, 20 kinases (STE), and containing CDK, MAPK, GSK3, CLK (CMKC) families, showed that compound 24 was highly selective for LIMK2, even against the closely related LIMK1. A co-crystal structure of $\mathbf{2 5}$ and LIMK2 showed binding away from the hinge region and occupation of the allosteric hydrophobic pocket formed through the DFG-out conformational change instead (Goodwin et al., 2015).<smiles>CN(Cc1ccc(C(O)CO)cc1)C(=O)c1ccc(S(=O)(=O)Nc2ccccc2)cc1</smiles>

23

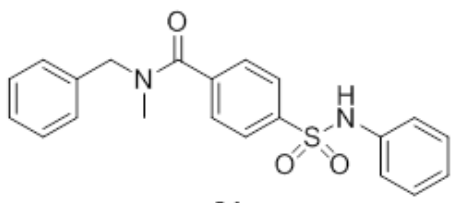

24

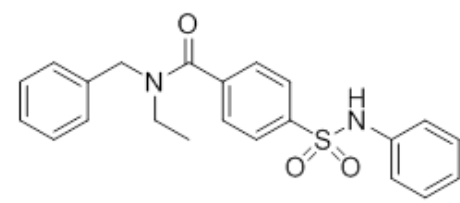

25

Fig. 7. Allosteric LIMK2 inhibitors.

\subsection{PKC inhibitors}

A series of 1,3,5-trisubstitued pyrazolines, such as compound $26\left(\mathrm{IC}_{50}: 0.3 \mu \mathrm{M}\right)$ (Fig. 8), was recently developed as selective allosteric inhibitors of the atypical isoform of the protein kinase $\mathrm{C}$ (PKC) family $\mathrm{PKC} \zeta$, which is being studied as a therapeutic target in allergic and inflammatory disease (Diaz-Meco \& Moscat, 2012). Compound 26 was assumed to bind with the PDK1interacting fragment (PIF) pocket, also known as hydrophobic motif pocket of PKC show significant inhibition against any other PKC isoforms and some related kinases in the AGC family at a concentration of $10 \mu \mathrm{M}$ (Abdel-Halim et al., 2014).

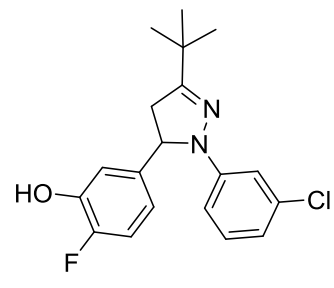

26

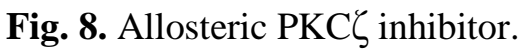


Phosphoinositide-dependent kinase-1 (PDK1) masters the activation of more than 20 downstream AGC kinases such as Akt and PKC and has been validated as a potential target for anticancer therapy. The PIF binding pocket is a $\alpha \mathrm{C}$-helix patch, which is a functionally conserved allosteric site on the AGC family of serine/threonine kinases and various other serine/threonine and tyrosine kinases. Several diaryl sulfonamides were screened as allosteric inhibitors of PDK1 by using a PIF-site directed chemical screening approach involving a fluorescence polarization competitive binding assay. Representative compounds RS1 (27) and RS2 (28) showed $\mathrm{K}_{\mathrm{d}}$ values of 1.5 and $9 \mu \mathrm{M}$ (Fig. 9). RS1 is able to freely diffuse into cells and enhance the effect of ATPcompetitive inhibitors of PDK1 to block activation of S6K1 and Akt in human embryonic kidney cells (Rettenmaier et al., 2014).

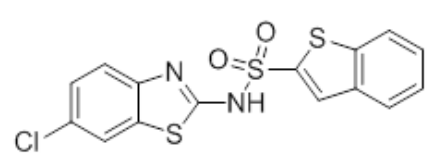

RS1 (27)

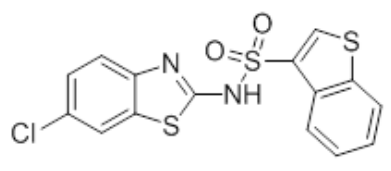

RS2 (28)

Fig. 9. Allosteric PDK1 inhibitors.

\subsection{RIP1 inhibitors}

The receptor-interacting protein kinase 1 (RIP1) is a critical upstream signaling molecule in inflammatory signaling and cell death pathways including apoptosis and necrosis factor $\alpha$ induced necroptosis (Ofengeim \& Yuan, 2013). A series of necrostatin analogues that bind in a hydrophobic pocket formed due to the DFG-out pocket of the inactive conformation of RIP1 are among few reported examples of allosteric RIP1 inhibitors. Representative compound Nec-1a showed $\mathrm{IC}_{50}$ values of $0.3 \mu \mathrm{M}, 1.2 \mu \mathrm{M}$, and $3.2 \mu \mathrm{M}$, against wild-type RIP1, RIP1 S161A mutant, and RIP1 S161E mutant, respectively (Xie et al., 2013) (Fig. 10). 


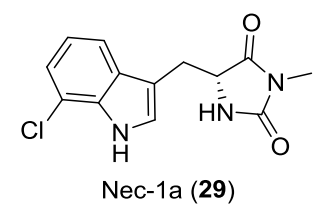

Fig. 10. Allosteric RIP1 inhibitor.

\subsection{PAK inhibitors}

Starting from a fragment-based screening hit, a series of dibenzodiazepine compounds, such as compounds 30 ( $\left.\mathrm{IC}_{50}: 18 \mathrm{nM}\right)$ and 31 ( $\left.\mathrm{IC}_{50}: 5 \mathrm{nM}\right)$ (Fig. 11), were obtained as highly selective p21activated kinase 1 (PAK1) inhibitors that bind in an allosteric pocket formed by the gatekeeper residue of PAK1 (Met344), $\alpha$ C-helix, and the DFG-out conformation. The optimized compound 31 demonstrated an exceptional selectivity profile against other known kinases, including PAK2 that shares 93\% kinase domain homology with PAK1. In addition, compound $\mathbf{3 1}$ showed good physicochemical properties and no significant CYP450s inhibition, albeit its short half time of 3.5 min in rat liver microsomes indicated limitations for further in vivo application (Karpov et al., 2015).

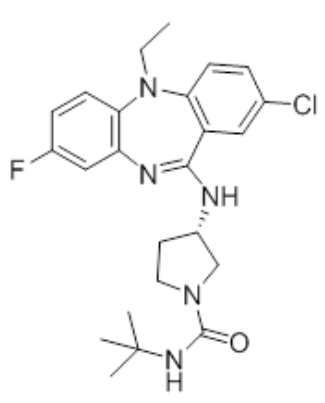

30
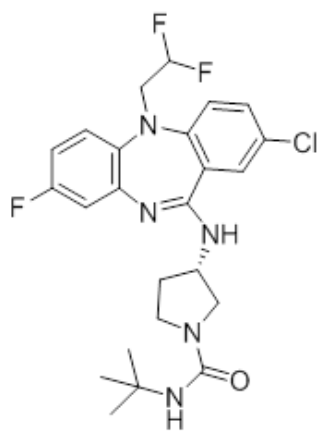

31

Fig. 11. Allosteric PAK inhibitors.

3.9 IRE1 inhibitors 
The inositol requiring enzyme 1 (IRE1), a serine/threonine kinase that possesses endonuclease activity, has been pursued as an anticancer target because of its role in maintaining protein synthesis homeostasis through the unfolded protein response cascade (Walter \& Ron, 2011). Harrington et al. reported the identification of selective inhibitors of IRE1 $\alpha$, such as the naphthalenylarylsulfonamide 32 ( $\mathrm{IC}_{50}: 14 \mathrm{nM}$, Fig. 12), which binds in an allosteric pocket formed following the $\alpha \mathrm{C}$-helix shift of IRE1 $\alpha$ (PDB ID 4U6R, $2.5 \AA$ ). However, the fact that no significant cytotoxicity was observed when compound 32 was screened against more than 200 tumor cell lines suggests that selective IRE1 $\alpha$ inhibitors may not be efficient antitumor agents (Harrington et al., 2015).

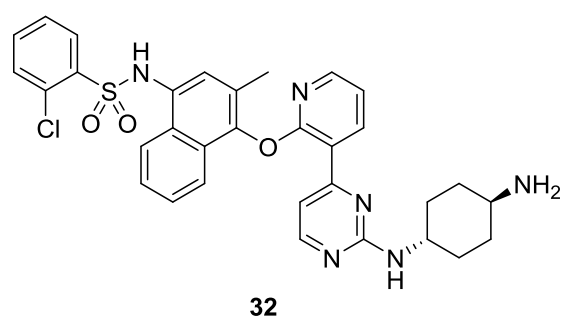

Fig. 12. Allosteric IRE1 inhibitor.

\subsection{CHK1 inhibitors}

Checkpoint kinase 1 (CHK1), a serine/threonine kinase belonging to the calcium/calmodulindependent protein kinase (CAMK) family, plays a critical role in protecting cells from DNA damage and regulating various mechanisms of DNA repair. Thus, the development of small molecule CHK1 inhibitor as chemopotentiators and single-agent therapies has attracted considerable interest (McNeely et al., 2014). Among the reported inhibitors of CHK1 are a few molecules, represented by the carbamate compound 33, semicarbazide compound 34, and quinazolinone compound 35 (Fig. 13), which bind in an allosteric pocket adjacent to the peptide substrate binding site of CHK1 (Converso et al., 2009; Vanderpool et al., 2009). All these allosteric 
inhibitors were revealed in 2009, and no recent examples of new allosteric CHK1 inhibitors have been reported since then.

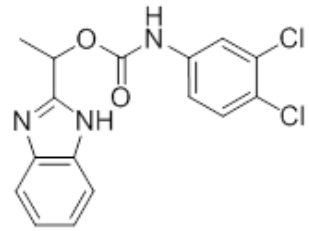

33

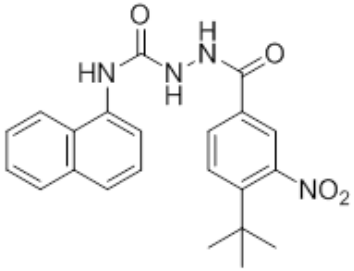

34

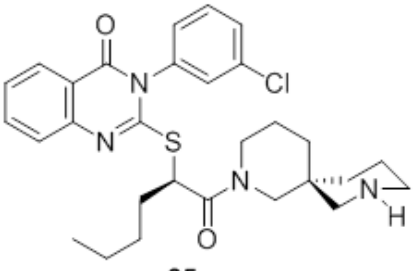

35

Fig. 13. Allosteric CHK1 inhibitors.

\section{Allosteric tyrosine kinase inhibitors}

\subsection{Abl inhibitors}

GNF-2 (36) was discovered by a phenotypic screening and demonstrated to bind to the myristoyl pocket of the C-lobe of the kinase domain (Fig. 1b), wand stands out as the first identified type IV inhibitor of Abl. A series of 1,3,4-thiadiazole compounds were recently reported as promising Abl inhibitors. A kinetic study showed that the lead compound BO1 (37) inhibited Abl T315I in an ATP-independent manner (Fallacara et al., 2014). Pyrazolo[3,4- $d]$ pyrimidine is a common scaffold found in small molecules with inhibitory activities against PI3Ks, Src, Abl, and several other kinases (Schenone et al., 2014). A target-based approach performed by the same group provided a library of highly functionalized pyrazolo[3,4- $d]$ pyrimidines and led to the discovery of a series of potential allosteric inhibitors of $\mathrm{Abl}$. The most potent compound $\mathbf{3 8}$ showed an $\mathrm{IC}_{50}$ value of 3.16 $\mu \mathrm{M}$ against Abl T315I, which was independent of the concentration of ATP and the peptide substrate (Vignaroli et al., 2014) (Fig. 14). 
<smiles>NC(=O)c1cccc(-c2cc(Nc3ccc(OC(F)(F)F)cc3)ncn2)c1</smiles>
GNF-2 (36)

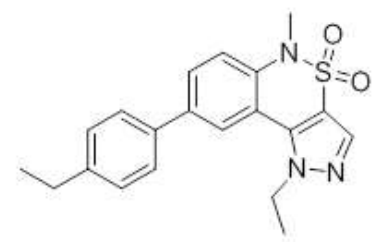

39<smiles>O=C(Nc1nnc(SCc2ccc(F)cc2)s1)c1ccc(F)cc1</smiles>

$\mathrm{BO} 1(37)$

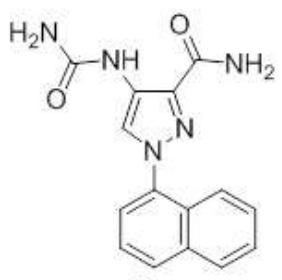

41
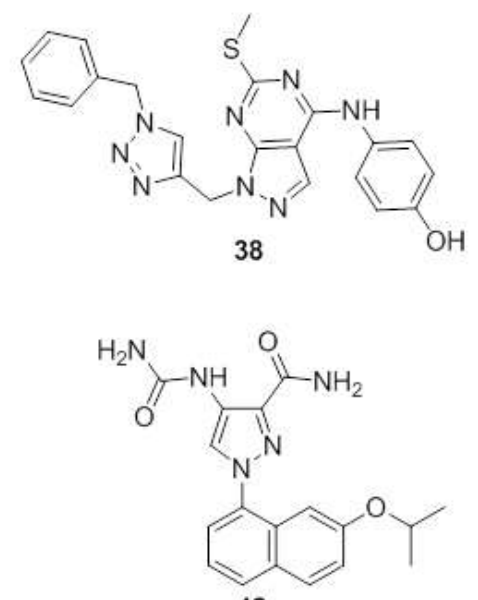

42<smiles>N#Cc1ccc2[nH]cc(CCCCN3CCC(NC(=O)c4cccc5c(C#N)c[nH]c45)CC3)c2c1</smiles>

Fig. 14. Allosteric tyrosine kinase inhibitors discussed in this paper.

\subsection{FAK inhibitors}

By functioning as a switch in signaling transduction, focal adhesion kinase (FAK) has been correlated with metastatic disease and studied as a potential anticancer target (Lee et al., 2015). Tricyclic sulfonamide compound 39 (FAK kinase domain $\mathrm{IC}_{50}: \sim 1 \mu \mathrm{M}$, and $\mathrm{FAK}$ full length $\mathrm{IC}_{50}$ : 3-9 $\mu \mathrm{M}$ ) was identified as a selective FAK inhibitor that binds in an allosteric pocket of the C-lobe. In contrast, compound $\mathbf{4 0}$ without the $N$-ethyl substituent is a dual ATP competitive and non-ATP competitive inhibitor that showed $\mathrm{IC}_{50}$ values ranging from 1 to $10 \mu \mathrm{M}$ against several kinases in a profiling assay, and it showed equivalent inhibitory potency against phosphorylated and unphosphorylated FAK (Iwatani et al., 2013) (Fig. 14).

\subsection{ITK inhibitors}


Interleukin-2-inducible T-cell kinase (ITK) is an important target for autoimmune and inflammatory disease. Started from a naphthalenylpyrazole hit 41 (ITK kinase domain, IC $_{50}: 0.11$ $\mu \mathrm{M}$; ITK full length, $\mathrm{IC}_{50}: 12.4 \mu \mathrm{M}$ ) that binds simultaneously at the ATP site and an adjacent allosteric site, compound 42 (ITK kinase domain, $\mathrm{IC}_{50}$ : $20 \mathrm{nM}$; ITK full length, $\mathrm{IC}_{50}: 4.99 \mu \mathrm{M}$ ) was identified as the first allosteric inhibitor of ITK that occupies a pocket adjacent to the ATP binding pocket. It is worth mentioning that surface plasmon resonance and NMR studies indicated a low binding affinity of compound $\mathbf{4 2}$ in the ATP binding pocket. In contrast to the promiscuous kinase inhibitor 41, compound 42 showed high selectivity for ITK in binding assays, which might be explained by the steric clash between the isopropyl substituent of $\mathbf{4 2}$ and the glycine loop of the ATP binding site that attenuate binding with other kinases. In addition, compound $\mathbf{4 2}$ inhibited cytokine production in human whole blood and T-cells (Han et al., 2014).

\subsection{IGF-1R inhibitors}

High-throughput screening campaigns against compound collections of Merck Serono led to the identification and development of a series of bisindole derivatives as allosteric inhibitors of receptor tyrosine kinase insulin-like growth factor-1 receptor (IGF-1R). Representative compound 43 occupies a pocket adjacent to the ATP-binding pocket and the activation loop (PDB ID: 3LW0, $1.79 \AA$ ) , and showed an $\mathrm{IC}_{50}$ value of $0.4 \mu \mathrm{M}$ against IGF-1R (Heinrich et al., 2010).

\section{Other allosteric kinase inhibitors}

\subsection{PI3K inhibitor}

Lipid kinases PI3Ks have been extensively studies as a key knot along the PI3K/Akt/mTOR pathway that is frequently deregulated in human cancers. Among the numerous inhibitors developed for the isoforms of PI3K, a group of arylmorpholine or morpholinochromone derivatives and analogues stands out (Houédé \& Pourquier, 2015; P. Wu \& Hu, 2012; P. Wu et al., 2012). One 
such compound, the pan-PI3K inhibitor PIK-108 (44, Fig. 15), has been shown to bind in an allosteric site close to the mutation hotspot of H1047R in the PI3K $\alpha$ C-lobe, in addition to its binding at the ATP-binding pocket (Hon et al., 2012).

\section{2 mTOR inhibitors}

mTOR is a member of a group of large, atypical serine/threonine kinases named as phosphatidylinositol 3-kinase-like protein kinases (PIKK) that share high sequence similarity with PI3Ks. Being another important knot along the PI3K signaling pathway, mTOR has been intensely investigated as an anticancer target. Besides ATP-competitive small-molecule mTOR inhibitors and dual $\mathrm{PI} 3 \mathrm{~K} / \mathrm{mTOR}$ inhibitors, a series of macrocyclic rapamycin analogs, or rapalogs, including FDA-approved everolimus and temsirolimus, which allosterically inhibit mTORC1, were among the successful examples of approved agents targeting the PI3K pathway (P. Wu \& Hu, 2010).

\subsection{IKKs inhibitors}

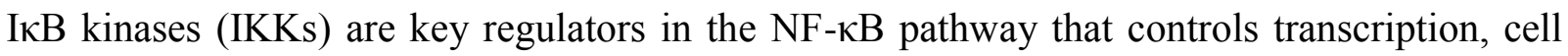
survival, immune responses, thus small IKK inhibitors have been studied as potential therapeutics for inflammatory disorders and cancer (DiDonato et al., 2012). Early reported allosteric inhibitor of IKKs includes BMS-345541 (45, IKK $\alpha, \mathrm{IC}_{50}: 4 \mu \mathrm{M}$, IKK $\beta$, IC50: $0.3 \mu \mathrm{M}$ ) (Burke et al., 2003) (Fig. 14). Besides synthetic small molecule inhibitors, the natural product ainsliadimer A (46) was recently identified as a potent irreversible covalent and allosteric inhibitor of IKK $\beta$ (Dong et al., 2015).

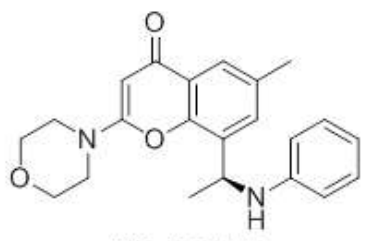

PIK-108 (44)

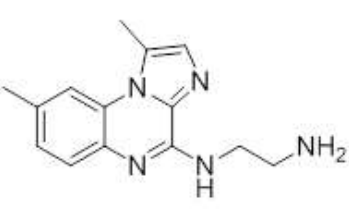

BMS-345541 (45)

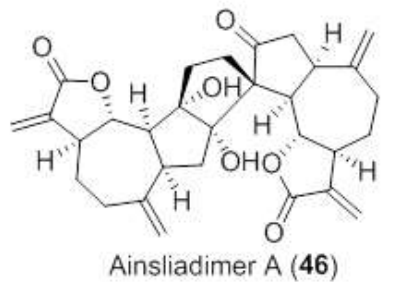

Ainsliadimer A (46) 
Fig. 15. Other allosteric kinase inhibitors.

\section{Perspectives}

Since active kinases are used in most screening assays, novel assays are needed to identify allosteric inhibitors. Most reported allosteric SMKIs were discovered by serendipity and confirmed by a co-crystalized structure with corresponding kinases, and although assays for the detecting of allosteric binding are gradually emerging (Fang et al., 2015) (R. Schneider et al., 2012; Simard, Getlik, et al., 2009; Taipale et al., 2013), a systematic approach for the identification of allosteric SMKIs is still missing. Structural information based on co-crystallization provides the most convincing evidence for allosteric inhibitory binding. However, the generation of a co-crystal structure for SMKIs with kinases may not be a practical solution for every potential allosteric inhibitor in question, and it is advisable to examine the possibility of any allosteric inhibition, such as by docking simulations using the whole kinase domain.

Other frequently debated topics centered on allosteric SMKIs deserve attention. Firstly, the main advantage offered by allosteric inhibition is the potential to achieve high selectivity and overcome drug resistance. Although resistance to SMKIs occurs frequently within the hinge region, it also happens in other parts of the kinase domain or even beyond the kinase domain. Mutationrelated resistance is likely to occur in allosteric sites due to the fact that they are not as essential for kinase functions as the ATP binding site.

Secondly, due to the hydrophobic properties of most allosteric pockets, the majority of allosteric inhibitors are lipophilic compounds with poor solubility and bioavailability. An additional solubilizing group might be needed to improve the pharmacokinetic properties of these compounds, and salt forms can be formulated for oral administration in clinical use. 
Third, further investigation on the biological and structural basis is needed to provide crucial information for future design of optimal SMKIs. One major challenge stems from the inherent flexibility of most kinase structures. For a limited number of kinases, both the kinase off-state structure and kinase-SMKI complex structure have been successfully solved, and this renders a direct comparison possible, thus identifying any SMKI-induced changes. For the majority of kinases targeted so far, most crystal structures solved are the ones complexed with SMKIs. The fact that some of the allosteric pockets are likely to engage in protein-protein and protein-peptide interactions further complicates the issue.

In terms of therapeutic indication, the lack of selectivity of most SMKIs generally does not hamper cancer treatment. However, this issue will probably translate into unacceptable side effects in therapeutic areas outside oncology, especially in chronic diseases, for which selective allosteric SMKIs may be used as most promising lead candidates. It is a widely accepted notion that combination strategies, such as the combination of targeted drugs with traditional chemo- or immunotherapy, are beneficial in cancers treatment. Thus, it is reasonable to expect that combination therapy strategies with all types of SMKIs, including ATP-competitive inhibitors, allosteric inhibitors, and covalent inhibitors, might lead to complete kinase suppression and favorable anticancer outcomes in clinical settings within oncology.

\section{Conclusion}

With the prospect of achieving high selectivity, allosteric inhibitors, as exemplified in this manuscript, offer means of kinase inhibition complementary to existing inhibitors targeting the highly-conserved ATP binding pockets. The allosteric pockets utilized by type III inhibitors usually involve the structural arrangement of the DFG-motif at the beginning of the activation loop and/or 
the displacement of the conserved structural $\alpha \mathrm{C}$-helix at the N-lobe of the kinase domain. Type IV inhibitors that bind into distinct allosteric pockets distal from the ATP site have been less studied. Research on allosteric SMKIs is currently on the frontline of kinase research, as demonstrated by the approval of trametinib in 2013, the progression of more than 10 advanced molecules in clinical trials of different phases, and a burgeoning pipeline of preclinical allosteric SMKIs with excellent specificity and potency profiles. In spite of the advantages offered by allosteric inhibitors, the field remains impacted by some controversial issues that need to be appropriately addressed to complete the process from laboratory bench to patients' bedside. After all, identifying an allosteric SMKI is easier than making a clinically approved SMKI.

\section{Conflicts of interest}

The authors declare that there are no conflicts of interest.

\section{Acknowledgement}

The Lundbeck Foundation (R140/141-2013-13835) is gratefully acknowledged for financial support. 


\section{References}

Abdel-Halim, M., Diesel, B., Kiemer, A. K., Abadi, A. H., Hartmann, R. W., \& Engel, M. (2014). Discovery and optimization of 1,3,5-trisubstituted pyrazolines as potent and highly selective allosteric inhibitors of protein kinase C-孔. J. Med. Chem., 57, 6513-6530.

Abe, H., Kikuchi, S., Hayakawa, K., lida, T., Nagahashi, N., Maeda, K., Sakamoto, J., Matsumoto, N., Miura, T., Matsumura, K., Seki, N., Inaba, T., Kawasaki, H., Yamaguchi, T., Kakefuda, R., Nanayama, T., Kurachi, H., Hori, Y., Yoshida, T., Kakegawa, J., Watanabe, Y., Gilmartin, A. G., Richter, M. C., Moss, K. G., \& Laquerre, S. G. (2011). Discovery of a highly potent and selective MEK inhibitor: GSK1120212 (JTP74057 DMSO solvate). ACS Med. Chem. Lett., 2, 320-324.

Ashwell, M. A., Lapierre, J.-M., Brassard, C., Bresciano, K., Bull, C., Cornell-Kennon, S., Eathiraj, S., France, D. S., Hall, T., Hill, J., Kelleher, E., Khanapurkar, S., Kizer, D., Koerner, S., Link, J., Liu, Y., Makhija, S., Moussa, M., Namdev, N., Nguyen, K., Nicewonger, R., Palma, R., Szwaya, J., Tandon, M., Uppalapati, U., Vensel, D., Volak, L. P., Volckova, E., Westlund, N., Wu, H., Yang, R.-Y., \& Chan, T. C. K. (2012). Discovery and optimization of a series of 3-(3-phenyl-3H-imidazo[4,5-b]pyridin-2-yl)pyridin-2amines: orally bioavailable, selective, and potent ATP-independent Akt inhibitors. J. Med. Chem., 55, 5291-5310.

Burke, J. R., Pattoli, M. A., Gregor, K. R., Brassil, P. J., MacMaster, J. F., Mclntyre, K. W., Yang, X., lotzova, V. S., Clarke, W., Strnad, J., Qiu, Y., \& Zusi, F. C. (2003). BMS-345541 is a highly selective inhibitor of IKB kinase that binds at an allosteric site of the enzyme and blocks NF-KB-dependent transcription in mice. J. Biol. Chem., 278, 1450-1456.

Comess, K. M., Sun, C., Abad-Zapatero, C., Goedken, E. R., Gum, R. J., Borhani, D. W., Argiriadi, M., Groebe, D. R., Jia, Y., Clampit, J. E., Haasch, D. L., Smith, H. T., Wang, S., Song, D., Coen, M. L., Cloutier, T. E., Tang, H., Cheng, X., Quinn, C., Liu, B., Xin, Z., Liu, G., Fry, E. H., Stoll, V., Ng, T. I., Banach, D., Marcotte, D., Burns, D. J., Calderwood, D. J., \& Hajduk, P. J. (2011). Discovery and characterization 
of non-ATP site inhibitors of the Mitogen Activated Protein (MAP) kinases. ACS Chem. Biol., 6, 234244.

Converso, A., Hartingh, T., Garbaccio, R. M., Tasber, E., Rickert, K., Fraley, M. E., Yan, Y., Kreatsoulas, C., Stirdivant, S., Drakas, B., Walsh, E. S., Hamilton, K., Buser, C. A., Mao, X., Abrams, M. T., Beck, S. C., Tao, W., Lobell, R., Sepp-Lorenzino, L., Zugay-Murphy, J., Sardana, V., Munshi, S. K., Jezequel-Sur, S. M., Zuck, P. D., \& Hartman, G. D. (2009). Development of thioquinazolinones, allosteric Chk1 kinase inhibitors. Bioorg. Med. Chem. Lett., 19, 1240-1244.

Cowan-Jacob, S. W., Jahnke, W., \& Knapp, S. (2014). Novel approaches for targeting kinases: allosteric inhibition, allosteric activation and pseudokinases. Future Med. Chem., 6, 541-561.

Davis, M. I., Hunt, J. P., Herrgard, S., Ciceri, P., Wodicka, L. M., Pallares, G., Hocker, M., Treiber, D. K., \& Zarrinkar, P. P. (2011). Comprehensive analysis of kinase inhibitor selectivity. Nat. Biotechnol., 29, 1046-1051.

Diaz-Meco, M. T., \& Moscat, J. (2012). The atypical PKCs in inflammation: NF-KB and beyond. Immunol. Rev., $246,154-167$

DiDonato, J. A., Mercurio, F., \& Karin, M. (2012). NF-KB and the link between inflammation and cancer. Immunol. Rev., 246, 379-400.

Dong, T., Li, C., Wang, X., Dian, L., Zhang, X., Li, L., Chen, S., Cao, R., Li, L., Huang, N., He, S., \& Lei, X. (2015). Ainsliadimer A selectively inhibits IKK $\alpha / \beta$ by covalently binding a conserved cysteine. Nat. Commun., 6.

Eroglu, Z., Tawbi, H. A., Hu, J., Guan, M., Frankel, P. H., Ruel, N. H., Wilczynski, S., Christensen, S., Gandara, D. R., \& Chow, W. A. (2015). A randomised phase II trial of selumetinib vs selumetinib plus temsirolimus for soft-tissue sarcomas. Br. J. Cancer, 112, 1644-1651.

Fabbro, D., Cowan-Jacob, S. W., \& Moebitz, H. (2015). Ten things you should know about protein kinases: IUPHAR Review 14. Br. J. Pharmacol., 172, 2675-2700. 
Fallacara, A. L., Tintori, C., Radi, M., Schenone, S., \& Botta, M. (2014). Insight into the allosteric inhibition of Abl kinase. J. Chem. Inf. Model., 54, 1325-1338.

Fang, Z., Grütter, C., \& Rauh, D. (2013). Strategies for the selective regulation of kinases with allosteric modulators: exploiting exclusive structural features. ACS Chem. Biol., 8, 58-70.

Fang, Z., Simard, J. R., Plenker, D., Nguyen, H. D., Phan, T., Wolle, P., Baumeister, S., \& Rauh, D. (2015). Discovery of Inter-Domain Stabilizers-A Novel Assay System for Allosteric Akt Inhibitors. ACS Chem. Biol., 10, 279-288.

Fasano, M., Della Corte, C. M., Califano, R., Capuano, A., Troiani, T., Martinelli, E., Ciardiello, F., \& Morgillo, F. (2014). Type III or allosteric kinase inhibitors for the treatment of non-small cell lung cancer. Expert Opin. Investig. Drugs, 23, 809-821.

Foda, Z. H., \& Seeliger, M. A. (2014). Kinase inhibitors: An allosteric add-on. Nat. Chem. Biol., 10, 796-797.

Fruman, D. A., \& Rommel, C. (2014). PI3K and cancer: lessons, challenges and opportunities. Nat. Rev. Drug Discov., 13, 140-156.

Gibbons, D. L., Pricl, S., Kantarjian, H., Cortes, J., \& Quintás-Cardama, A. (2012). The rise and fall of gatekeeper mutations? The BCR-ABL1 T315I paradigm. Cancer, 118, 293-299.

Goodwin, N. C., Cianchetta, G., Burgoon, H. A., Healy, J., Mabon, R., Strobel, E. D., Allen, J., Wang, S., Hamman, B. D., \& Rawlins, D. B. (2015). Discovery of a type III inhibitor of LIM kinase 2 that binds in a DFG-out conformation. ACS Med. Chem. Lett., 6, 53-57.

Gower, C. M., Chang, M. E. K., \& Maly, D. J. (2014). Bivalent inhibitors of protein kinases. Crit. Rev. Biochem. Mol. Biol., 49, 102-115.

Han, S., Czerwinski, Robert M., Caspers, Nicole L., Limburg, David C., Ding, W., Wang, H., Ohren, Jeffrey F., Rajamohan, F., McLellan, Thomas J., Unwalla, R., Choi, C., Parikh, Mihir D., Seth, N., Edmonds, J., Phillips, C., Shakya, S., Li, X., Spaulding, V., Hughes, S., Cook, A., Robinson, C., Mathias, John P., Navratilova, I., Medley, Quintus G., Anderson, David R., Kurumbail, Ravi G., \& Aulabaugh, A. (2014). 
Selectively targeting an inactive conformation of interleukin-2-inducible T-cell kinase by allosteric inhibitors. Biochem. J., 460, 211-222.

Harrington, P. E., Biswas, K., Malwitz, D., Tasker, A. S., Mohr, C., Andrews, K. L., Dellamaggiore, K., Kendall, R., Beckmann, H., Jaeckel, P., Materna-Reichelt, S., Allen, J. R., \& Lipford, J. R. (2015). Unfolded protein response in cancer: IRE1 $\alpha$ inhibition by selective kinase ligands does not impair tumor cell viability. ACS Med. Chem. Lett., 6, 68-72.

Hatzivassiliou, G., Haling, J. R., Chen, H., Song, K., Price, S., Heald, R., Hewitt, J. F. M., Zak, M., Peck, A., Orr, C., Merchant, M., Hoeflich, K. P., Chan, J., Luoh, S.-M., Anderson, D. J., Ludlam, M. J. C., Wiesmann, C., Ultsch, M., Friedman, L. S., Malek, S., \& Belvin, M. (2013). Mechanism of MEK inhibition determines efficacy in mutant KRAS- versus BRAF-driven cancers. Nature, 501, 232-236.

Heinrich, T., Grädler, U., Böttcher, H., Blaukat, A., \& Shutes, A. (2010). Allosteric IGF-1R Inhibitors. ACS Med. Chem. Lett., 1, 199-203.

Hirai, H., Sootome, H., Nakatsuru, Y., Miyama, K., Taguchi, S., Tsujioka, K., Ueno, Y., Hatch, H., Majumder, P. K., Pan, B.-S., \& Kotani, H. (2010). MK-2206, an allosteric Akt inhibitor, enhances antitumor efficacy by standard chemotherapeutic agents or molecular targeted drugs in vitro and in vivo. Mol. Cancer Ther., 9, 1956-1967.

Hon, W. C., Berndt, A., \& Williams, R. L. (2012). Regulation of lipid binding underlies the activation mechanism of class IA PI3-kinases. Oncogene, 31, 3655-3666.

Houédé, N., \& Pourquier, P. (2015). Targeting the genetic alterations of the PI3K-AKT-mTOR pathway: Its potential use in the treatment of bladder cancers. Pharmacol. Ther., 145, 1-18.

Iwatani, M., Iwata, H., Okabe, A., Skene, R. J., Tomita, N., Hayashi, Y., Aramaki, Y., Hosfield, D. J., Hori, A., Baba, A., \& Miki, H. (2013). Discovery and characterization of novel allosteric FAK inhibitors. Eur. J. Med. Chem., 61, 49-60.

Johnson, L. N., \& Lewis, R. J. (2001). Structural basis for control by phosphorylation. Chem. Rev., 101, 22092242. 
Jänne, P. A., Shaw, A. T., Pereira, J. R., Jeannin, G., Vansteenkiste, J., Barrios, C., Franke, F. A., Grinsted, L., Zazulina, V., Smith, P., Smith, I., \& Crinò, L. (2013). Selumetinib plus docetaxel for KRAS-mutant advanced non-small-cell lung cancer: a randomised, multicentre, placebo-controlled, phase 2 study. Lancet Oncol., 14, 38-47.

Karpov, A. S., Amiri, P., Bellamacina, C., Bellance, M.-H., Breitenstein, W., Daniel, D., Denay, R., Fabbro, D., Fernandez, C., Galuba, I., Guerro-Lagasse, S., Gutmann, S., Hinh, L., Jahnke, W., Klopp, J., Lai, A., Lindvall, M. K., Ma, S., Möbitz, H., Pecchi, S., Rummel, G., Shoemaker, K., Trappe, J., Voliva, C., Cowan-Jacob, S. W., \& Marzinzik, A. L. (2015). Optimization of a Dibenzodiazepine Hit to a Potent and Selective Allosteric PAK1 Inhibitor. ACS Med. Chem. Lett., 6, 776-781.

Lamba, V., \& Ghosh, I. (2012). New directions in targeting protein kinases: focusing upon true allosteric and bivalent inhibitors. Curr. Pharm. Design, 18, 2936-2945.

Larkin, J., Ascierto, P. A., Dréno, B., Atkinson, V., Liszkay, G., Maio, M., Mandalà, M., Demidov, L., Stroyakovskiy, D., Thomas, L., de la Cruz-Merino, L., Dutriaux, C., Garbe, C., Sovak, M. A., Chang, I., Choong, N., Hack, S. P., McArthur, G. A., \& Ribas, A. (2014). Combined vemurafenib and cobimetinib in BRAF-mutated melanoma. N. Eng. J. Med., 371, 1867-1876.

Lee, B. Y., Timpson, P., Horvath, L. G., \& Daly, R. J. (2015). FAK signaling in human cancer as a target for therapeutics. Pharmacol. Ther., 146, 132-149.

Lindsley, C. W. (2010). The Akt/PKB family of protein kinases: a review of small molecule inhibitors and progress towards target validation: a 2009 update. Curr. Top. Med. Chem., 10, 458-477.

Long, G. V., Stroyakovskiy, D., Gogas, H., Levchenko, E., de Braud, F., Larkin, J., Garbe, C., Jouary, T., Hauschild, A., Grob, J. J., Chiarion Sileni, V., Lebbe, C., Mandalà, M., Millward, M., Arance, A., Bondarenko, I., Haanen, J. B. A. G., Hansson, J., Utikal, J., Ferraresi, V., Kovalenko, N., Mohr, P., Probachai, V., Schadendorf, D., Nathan, P., Robert, C., Ribas, A., DeMarini, D. J., Irani, J. G., Casey, M., Ouellet, D., Martin, A.-M., Le, N., Patel, K., \& Flaherty, K. (2014). Combined BRAF and MEK inhibition versus BRAF inhibition alone in melanoma. N. Eng. J. Med., 371, 1877-1888. 
Lu, H., \& Schulze-Gahmen, U. (2006). Toward understanding the structural basis of Cyclin-Dependent Kinase 6 specific inhibition. J. Med. Chem., 49, 3826-3831.

McNeely, S., Beckmann, R., \& Bence Lin, A. K. (2014). CHEK again: Revisiting the development of CHK1 inhibitors for cancer therapy. Pharmacol. Ther., 142, 1-10.

Norman, R. A., Toader, D., \& Ferguson, A. D. (2012). Structural approaches to obtain kinase selectivity. Trends Pharmacol. Sci., 33, 273-278.

Ofengeim, D., \& Yuan, J. (2013). Regulation of RIP1 kinase signalling at the crossroads of inflammation and cell death. Nat. Rev. Mol. Cell Biol., 14, 727-736.

Okamoto, K., Ikemori-Kawada, M., Jestel, A., von König, K., Funahashi, Y., Matsushima, T., Tsuruoka, A., Inoue, A., \& Matsui, J. (2015). Distinct binding mode of multikinase inhibitor lenvatinib revealed by biochemical characterization. ACS Med. Chem. Lett., 6, 89-94.

Over, B., Wetzel, S., Grütter, C., Nakai, Y., Renner, S., Rauh, D., \& Waldmann, H. (2013). Natural-productderived fragments for fragment-based ligand discovery. Nat. Chem., 5, 21-28.

Pitts, T. M., Davis, S. L., Eckhardt, S. G., \& Bradshaw-Pierce, E. L. (2014). Targeting nuclear kinases in cancer: Development of cell cycle kinase inhibitors. Pharmacol. Ther., 142, 258-269.

Rask-Andersen, M., Zhang, J., Fabbro, D., \& Schiöth, H. B. (2014). Advances in kinase targeting: current clinical use and clinical trials. Trends Pharmacol. Sci., 35, 604-620.

Rastelli, G., Anighoro, A., Chripkova, M., Carrassa, L., \& Broggini, M. (2014). Structure-based discovery of the first allosteric inhibitors of cyclin-dependent kinase 2. Cell Cycle, 13, 2296-2305.

Redwan, I. N., Dyrager, C., Solano, C., Fernández de Trocóniz, G., Voisin, L., Bliman, D., Meloche, S., \& Grøtli, M. (2014). Towards the development of chromone-based MEK1/2 modulators. Eur. J. Med. Chem., $85,127-138$.

Regan, J., Capolino, A., Cirillo, P. F., Gilmore, T., Graham, A. G., Hickey, E., Kroe, R. R., Madwed, J., Moriak, M., Nelson, R., Pargellis, C. A., Swinamer, A., Torcellini, C., Tsang, M., \& Moss, N. (2003). Structure-activity relationships of the p38 $\alpha$ MAP kinase inhibitor 1-(5-tert-Butyl-2-p-tolyl-2H- 
pyrazol-3-yl)-3-[4-(2-morpholin-4-yl-ethoxy)naph- thalen-1-yl]urea (BIRB 796). J. Med. Chem., 46, 4676-4686.

Rettenmaier, T. J., Sadowsky, J. D., Thomsen, N. D., Chen, S. C., Doak, A. K., Arkin, M. R., \& Wells, J. A. (2014). A small-molecule mimic of a peptide docking motif inhibits the protein kinase PDK1. Proc. Natl. Acad. Sci. USA, 111, 18590-18595.

Rice, K. D., Aay, N., Anand, N. K., Blazey, C. M., Bowles, O. J., Bussenius, J., Costanzo, S., Curtis, J. K., Defina, S. C., Dubenko, L., Engst, S., Joshi, A. A., Kennedy, A. R., Kim, A. I., Koltun, E. S., Lougheed, J. C., Manalo, J.-C. L., Martini, J.-F., Nuss, J. M., Peto, C. J., Tsang, T. H., Yu, P., \& Johnston, S. (2012). Novel carboxamide-based allosteric MEK inhibitors: discovery and optimization efforts toward XL518 (GDC-0973). ACS Med. Chem. Lett., 3, 416-421.

Robert, C., Karaszewska, B., Schachter, J., Rutkowski, P., Mackiewicz, A., Stroiakovski, D., Lichinitser, M., Dummer, R., Grange, F., Mortier, L., Chiarion-Sileni, V., Drucis, K., Krajsova, I., Hauschild, A., Lorigan, P., Wolter, P., Long, G. V., Flaherty, K., Nathan, P., Ribas, A., Martin, A.-M., Sun, P., Crist, W., Legos, J., Rubin, S. D., Little, S. M., \& Schadendorf, D. (2015). Improved overall survival in melanoma with combined dabrafenib and trametinib. N. Eng. J. Med., 372, 30-39.

Samatar, A. A., \& Poulikakos, P. I. (2014). Targeting RAS-ERK signalling in cancer: promises and challenges. Nat. Rev. Drug Discov., 13, 928-942.

Schenone, S., Radi, M., Musumeci, F., Brullo, C., \& Botta, M. (2014). Biologically driven synthesis of pyrazolo[3,4-d]pyrimidines as protein kinase inhibitors: an old scaffold as a new tool for medicinal chemistry and chemical biology studies. Chem. Rev., 114, 7189-7238.

Schneider, E. V., Böttcher, J., Huber, R., Maskos, K., \& Neumann, L. (2013). Structure-kinetic relationship study of CDK8/CycC specific compounds. Proc. Natl. Acad. Sci. USA, 110, 8081-8086.

Schneider, R., Becker, C., Simard, J. R., Getlik, M., Bohlke, N., Janning, P., \& Rauh, D. (2012). Direct binding assay for the detection of type IV allosteric inhibitors of Abl. J. Am. Chem. Soc., 134, 9138-9141. 
Simard, J. R., Getlik, M., Grütter, C., Pawar, V., Wulfert, S., Rabiller, M., \& Rauh, D. (2009). Development of a fluorescent-tagged kinase assay system for the detection and characterization of allosteric kinase inhibitors. J. Am. Chem. Soc., 131, 13286-13296.

Simard, J. R., Kluter, S., Grutter, C., Getlik, M., Rabiller, M., Rode, H. B., \& Rauh, D. (2009). A new screening assay for allosteric inhibitors of cSrc. Nat. Chem. Biol., 5, 394-396.

Taipale, M., Krykbaeva, I., Whitesell, L., Santagata, S., Zhang, J., Liu, Q., Gray, N. S., \& Lindquist, S. (2013). Chaperones as thermodynamic sensors of drug-target interactions reveal kinase inhibitor specificities in living cells. Nat. Biotech., 31, 630-637.

Vanderpool, D., Johnson, T. O., Ping, C., Bergqvist, S., Alton, G., Phonephaly, S., Rui, E., Luo, C., Deng, Y.-L., Grant, S., Quenzer, T., Margosiak, S., Register, J., Brown, E., \& Ermolieff, J. (2009). Characterization of the CHK1 allosteric inhibitor binding site. Biochemistry, 48, 9823-9830.

Vignaroli, G., Mencarelli, M., Sementa, D., Crespan, E., Kissova, M., Maga, G., Schenone, S., Radi, M., \& Botta, M. (2014). Exploring the chemical space around the privileged pyrazolo[3,4-d]pyrimidine scaffold: toward novel allosteric inhibitors of T315I-mutated Abl. ACS Comb. Sci., 16, 168-175.

Walter, P., \& Ron, D. (2011). The unfolded protein response: from stress pathway to homeostatic regulation. Science, 334, 1081-1086.

Weisner, J., Gontla, R., van der Westhuizen, L., Oeck, S., Ketzer, J., Janning, P., Richters, A., Mühlenberg, T., Fang, Z., Taher, A., Jendrossek, V., Pelly, S. C., Bauer, S., van Otterlo, W. A. L., \& Rauh, D. (2015). Covalent-allosteric kinase inhibitors. Angew. Chem.-Int. Edit., DOI: 10.1002/anie.201502142.

Wu, P., \& Hu, Y.-Z. (2010). PI3K/Akt/mTOR pathway inhibitors in cancer: a perspective on clinical progress. Curr. Med. Chem., 17, 4326-4341.

Wu, P., \& Hu, Y. (2012). Small molecules targeting phosphoinositide 3-kinases. MedChemComm, 3, 13371355.

Wu, P., Liu, T., \& Hu, Y. (2009). PI3K inhibitors for cancer therapy: what has been achieved so far? Curr. Med. Chem., 16, 916-930. 
Wu, P., Nielsen, T. E., \& Clausen, M. H. (2015a). FDA-approved small molecule kinase inhibitors. Trends Pharmacol. Sci., 36, 422-439.

Wu, P., Nielsen, T. E., \& Clausen, M. H. (2015b). Small-molecule kinase inhibitors: an analysis of FDAapproved drugs. Drug Discov. Today, DOI: 10.1016/j.drudis.2015.1007.1008.

Wu, P., Su, Y., Liu, X., Yan, J., Ye, Y., Zhang, L., Xu, J., Weng, S., Li, Y., Liu, T., Dong, X., Sun, M., Yang, B., He, Q., \& Hu, Y. (2012). Discovery of novel morpholino-quinoxalines as PI3K $\alpha$ inhibitors by pharmacophore-based screening. MedChemComm, 3, 659-662.

Wu, W.-I., Voegtli, W. C., Sturgis, H. L., Dizon, F. P., Vigers, G. P. A., \& Brandhuber, B. J. (2010). Crystal structure of human AKT1 with an allosteric inhibitor reveals a new mode of kinase inhibition. PLoS ONE, 5, e12913.

Xie, T., Peng, W., Liu, Y., Yan, C., Maki, J., Degterev, A., Yuan, J., \& Shi, Y. (2013). Structural Basis of RIP1 Inhibition by Necrostatins. Structure, 21, 493-499.

Yap, T. A., Yan, L., Patnaik, A., Tunariu, N., Biondo, A., Fearen, I., Papadopoulos, K. P., Olmos, D., Baird, R., Delgado, L., Tetteh, E., Beckman, R. A., Lupinacci, L., Riisnaes, R., Decordova, S., Heaton, S. P., Swales, K., deSouza, N. M., Leach, M. O., Garrett, M. D., Sullivan, D. M., de Bono, J. S., \& Tolcher, A. W. (2014). Interrogating two schedules of the AKT inhibitor MK-2206 in patients with advanced solid tumors incorporating novel pharmacodynamic and functional imaging biomarkers. Clin. Cancer Res., 20, 5672-5685.

Zhang, J., Adrian, F. J., Jahnke, W., Cowan-Jacob, S. W., Li, A. G., lacob, R. E., Sim, T., Powers, J., Dierks, C., Sun, F., Guo, G.-R., Ding, Q., Okram, B., Choi, Y., Wojciechowski, A., Deng, X., Liu, G., Fendrich, G., Strauss, A., Vajpai, N., Grzesiek, S., Tuntland, T., Liu, Y., Bursulaya, B., Azam, M., Manley, P. W., Engen, J. R., Daley, G. Q., Warmuth, M., \& Gray, N. S. (2010). Targeting Bcr-Abl by combining allosteric with ATP-binding-site inhibitors. Nature, 463, 501-506.

Zhao, Y., \& Adjei, A. A. (2014). The clinical development of MEK inhibitors. Nat. Rev. Clin. Oncol., 11, 385400. 
Zuccotto, F., Ardini, E., Casale, E., \& Angiolini, M. (2010). Through the "gatekeeper door": exploiting the active kinase conformation. J. Med. Chem., 53, 2681-2694. 